\title{
A reconstrução d' $O$ cortiço: estratégias de adaptação do romance de Aluísio Azevedo para um jogo de tabuleiro
}

\author{
The Remaking of The Slum: Strategies for Adapting \\ Aluísio Azevedo's Novel to a Board Game \\ La reconstrucción de $O$ cortiço: estrategias de adaptación \\ del romance de Aluísio Azevedo para un juego de mesa
}

Saulo Gomes Thimoteo*

\begin{abstract}
Resumo
Muitas são as formas de interação com as narrativas literárias: livros, filmes, histórias em quadrinhos, jogos etc. Com o século XXI, os métodos de adaptação ganharam força, realizando-se diversas ações de transformar histórias de um gênero em outro, criando uma série de referências que se vão cruzando e se ampliando. Nesse sentido, os jogos de tabuleiro também permitem um diálogo intertextual, recriando e evocando textos clássicos a partir de uma outra perspectiva de interação. Isso é o que se realiza no projeto de extensão "Adamastor: Laboratório de Criação de Jogos Literários", com caráter didático, para estimular a leitura literária e ampliar sua fruição para além de um mero jogo de perguntas e respostas de compreensão e interpretação. A título de exemplo, apresenta-se o processo de adaptação para um jogo de tabuleiro do romance naturalista $O$ cortiço, de Aluísio Azevedo, a partir dos conceitos teóricos de adaptação elaborados por Linda Hutcheon.
\end{abstract}

Palavras-chave: adaptação, jogos de tabuleiro, Aluísio Azevedo, material didático.

\begin{abstract}
There are many ways of interacting with literary narratives: books, movies, graphic novels, games etc. In the twentieth-first century, adaptation methods have gained strength, producing several strategies of transforming stories from one genre to another, creating a series of allusions that intersect and expand. In this sense, board games also allow for intertextual dialogue, recreating and evoking classical texts from another perspective of interaction. Such is the aim of the extension project "Adamastor: Laboratório de Criação de Jogos Literários," didactic in character, to stimulate literary reading and to go beyond a simple question-and-answer game of understanding and interpretation. As an example, this paper presents the adaptation process of Aluísio Azevedo's naturalist novel The Slum to a board game based on Linda Hutcheon's concepts of adaptation theory.
\end{abstract}

Keywords: adaptation, board games, Aluísio Azevedo, didactic material.

\section{Resumen}

Las formas de interacción con las narrativas literarias son muy variadas: libros, películas, cómics y juegos etc. En el siglo XXI, los métodos de adaptación ganan espacio, realizándose diversas acciones de transformar historias de un medio a otro, creando de este modo una serie de referencias que se van cruzando y ampliándose. En ese sentido, los juegos de mesa también permiten un diálogo intertextual, recreando $\mathrm{y}$ evocando textos clásicos desde otra perspectiva de interacción. Eso es lo que se lleva a cabo en el proyecto de extensión "Adamastor: Laboratório de Criação de Jogos Literários", con carácter didáctico, para promover la lectura literaria y ampliar su disfrute más allá de un simple juego de preguntas y respuestas de comprensión y interpretación. A modo de ejemplo, se presenta el proceso de adaptación como juego de mesa de la novela naturalista $O$ cortiço, de Aluísio Azevedo, basándose en conceptos de adaptación elaborados por Linda Hutcheon.

Palabras-clave: adaptación, juegos de mesa, Aluísio Azevedo, material didáctico.

\footnotetext{
Universidade Federal da Fronteira Sul (UFFS), Chapecó, SC, Brasil. (Dorcid.org/0000-0002-3874-9215. E-mail: sthimoteo@gmail.com
} 


\section{"Mudam-se os tempos, mudam-se as vontades": o cânone em adaptação}

Há muitas maneiras de abordar e envolver-se com uma obra literária para além da leitura tradicional. O cinema e a televisão são duas mídias que, desde o século $\mathrm{XX}$, realizaram diversas adaptações de obras clássicas da literatura, no sentido de socializar essas narrativas em outras mídias. As graphic novels expandem a forma de recepção da obra original, aliando ilustrações e a coesão dos quadrinhos como forma de estabelecer uma nova dinâmica na recepção do texto e da história, em seu enredo e personagens.

Contudo, não se pode tomar a adaptação como réplica do texto adaptado, já que os contextos de produção se alteram e os novos autores (com suas visões de mundo) criam um universo paralelo ao do autor original. Aliando-se a isso, no caso de uma adaptação para outra mídia (de um livro para uma história em quadrinhos, de um filme para um videogame), buscar-se a exatidão é algo impossível, pois a linguagem, e seus códigos, acaba por modificar-se também.

Há uma infinidade de abordagens possíveis, por meio de novas mídias, gêneros e suportes, de obras canônicas da literatura. Fazem-se versões infantis, ilustradas ou em HQs, de romances e contos, criam-se jogos (aplicativos, eletrônicos e de tabuleiro), montam-se podcasts, perfis em redes sociais e canais em plataformas como o YouTube para socialização da leitura e das impressões de leitores ou grupos de leitura. Felizmente, graças ao poder plástico da literatura, ela sobrevive e permite a própria metamorfose, permitindo-se a descoberta de novos sentidos e novas figuras e subvertendo o que poderia parecer inamovível.

Levando-se isso em conta, o projeto de extensão "Adamastor: Laboratório de Criação de Jogos Literários" desenvolve, a partir de textos clássicos de literatura de língua portuguesa, jogos didático-literários, que visam ao resgate e à problematização de textos literários e também a uma interação ativa do leitor com o texto, a partir de um novo suporte.

Nomes como Luís de Camões, Machado de Assis e Aluísio Azevedo, por exemplo, que trazem consigo o status de cânone, tendem a ser tratados como autores superiores e inacessíveis a leitores neófitos. Tal imagem cria barreiras e faz com que a construção de linguagem, de estilo, de representação das épocas e da sociedade presente em suas obras mantenha-se desconhecida ou, pelo menos, desassociada dos contextos dos leitores.

Como maneira de reversão desse distanciamento, a proposta da ressignificação de autores clássicos parte do pressuposto de Linda Hutcheon, em Uma teoria da adaptação, sobre as questões concernentes às adaptações e às evocações das narrativas e obras no processo diacrônico em que se vão sucedendo:

As histórias não são imutáveis; ao contrário, elas também evoluem por meio da adaptação ao longo dos anos. Em alguns casos, tal como ocorre na adaptação biológica, a adaptação cultural conduz a uma migração para condições mais favoráveis: as histórias viajam para diferentes culturas e mídias (Hutcheon, 2011, p. 58).

As "condições favoráveis" podem ser pensadas em uma série de possibilidades: a transposição de um romance para filme, a produção de livros a partir de seriados de sucesso, como spin-offs, ou seja, ao universo criado pelos autores podem suceder-se infinitas narrativas, expressas nos mais variados formatos, por vezes até explorando caminhos apenas pressentidos no texto original. Surge, então, uma maneira dos leitores reviverem a obra por outras vias, em diferentes contextos, sabendo que não será a mesma experiência, mas algo que a poderá complementar e ampliar.

E se os leitores e as próprias obras ganham com essa nova roupagem, a interação com tais textos no ambiente de sala de aula também ganha por possibilitar uma aproximação entre a diegese da obra e o repertório dos alunos. Por meio da adaptação em forma de jogo, a outra face da adaptação se faz presente: construir-se como etapa introdutória da obra literária, apresentando o contexto de produção da obra, os personagens, o enredo e o autor a partir de uma interação lúdica, desmistificadora por unir o dulce ao docere horacianos.

Tal articulação entre novos leitores e obras canônicas é importante, pois, conforme Carlos Reis aponta em Estudos literários e ensino da literatura: o jardim dos caminhos que se cruzam, é aos 
estudantes do século XXI, com bagagem de incontáveis horas de videogames e de outras incursões em plataformas digitais que

damos a ler Os Lusíadas, a poesia de Cesário Verde, O alienista ou a Mensagem, como se o mundo não tivesse mudado, desde que aquela literatura foi escrita e publicada e como se não tivesse havido drásticas mudanças no perfil sociocultural dos nossos estudantes e na sua relação com as narrativas literárias (Reis, 2018, p. 39).

Tal crítica não se refere aos textos literários mencionados per se, nem tampouco a uma pretensa incapacidade de leitura por parte dos alunos atuais. É no espaço de interação do livro com o leitor, e do papel do professor nesse trânsito, que reside essa necessidade de não mais julgar o professor como o "detentor do saber" e o aluno como mero espectador que deve responder a comandos. Da mesma forma, ao se lançar a prática de leitura literária como responsabilidade exclusiva do aluno, incorre-se em falta igualmente grave, pois aí se retira dos alunos a oportunidade de ter contato com textos clássicos que dificilmente seriam escolhidos por eles por iniciativa própria. Conforme Leyla Perrone-Moisés observa, em Mutações da literatura no século XXI: "Oferecer ao aluno apenas aquilo que já consta em seu repertório é subestimar sua capacidade de ampliar seus conhecimentos e privá-lo de um bem a que ele tem direito" (2016, p. 81). Por isso, como forma de conciliar ambas as abordagens, o tratamento do texto literário em diferentes suportes, em articulação com a obra e seu contexto, permite ao aluno/leitor participar ativamente do processo de leitura, mas também ter um contato estruturado e que mantém as principais características do universo criado pelo autor, apresentado em uma perspectiva alternativa.

Dentre alternativas de trabalho com o texto literário, a idealização da criação de jogos de tabuleiro, como material didático, inclusive, ampara-se no conceito de "agência", firmado por Janet Murray para games eletrônicos, mas que também se pode aplicar em jogos físicos. Para a pesquisadora, a "agência" ocorre com a realização de ações significativas e posterior visão empírica dos resultados de tais escolhas, ou seja, o "leitor" torna-se "agente" do universo narrativo, pois "como prazer estético, uma experiência a ser saboreada por si mesma, ela é oferecida de modo limitado nas formas de arte tradicionais, mas é mais comumente encontrada nas atividades estruturadas a que chamamos jogos" (Murray, 2003, p. 129). Tal limitação é apontada pela autora, nas "artes tradicionais", no sentido de não se possibilitar uma expansão para além do que se é contado ou mostrado. Como se verá na transposição do romance $O$ cortiço de Aluísio Azevedo para um jogo de tabuleiro, a representação dos personagens e da sua interação como evolução do enredo funcionam como uma via de mão dupla: há a dinâmica dos jogadores, na experiência lúdica do seu processo de enriquecimento e construção do próprio cortiço; e há a evocação contínua dos elementos do romance, como forma de rememoração.

Com isso, o projeto parte do princípio de que compreender a literatura (nas várias formas de manifestação) é compreender a noção de jogo que se estabelece no texto. Conforme Roland Barthes defende, em Da obra ao texto:

"Jogar" deve ser tomado aqui no sentido polissêmico do termo: o próprio texto joga (como uma porta, como um aparelho em que há "jogo"); e o leitor, ele joga duas vezes: joga com o Texto (sentido lúdico), busca uma prática que o re-produza; mas para que essa prática não se reduza a uma mimesis passiva, interior (o Texto é justamente aquilo que resiste a essa redução), ele joga o jogo de representar o Texto (Barthes, 1988, p. 77).

O jogo de Barthes é o jogo da linguagem viva que se materializa no texto. Se o texto se torna uma forma de jogo, em que se produz uma representação e no qual o leitor se assume como movimentador das peças dadas, um jogo evocador de uma narrativa também se pode tornar um texto. E, nesse caso, é um texto que se renova a cada partida e que obtém um desfecho aberto e, até então, desconhecido, pois o final (o vencedor) dependerá do avanço de cada jogador e de seu processo.

Mesmo que haja similaridades com o romance $O$ cortiço, especialmente no tocante a personagens e situações do enredo, o jogo não busca ser uma síntese dos acontecimentos, como forma alternativa de ler a obra sem a ler. Ele funciona, antes, como recodificação do texto 
original num conjunto revisitado de convenções e signos. Parte-se do universo de Aluísio Azevedo, mas como forma de criar em seus jogadores um misto de reconhecimento e surpresa: reconhecimento, por ver personagens como Rita Baiana, Pombinha ou Albino como moradores do cortiço que se constrói, lembrando de seus papéis no romance; surpresa por vê-los como parte de uma experiência de imersão.

\section{O jogo de tabuleiro d' $O$ cortiço: construir, morar, agir}

Conforme Carlos Reis salienta sobre o estudo e ensino de literatura, é necessário a compreensão de que ela "se desenvolve e aprofunda a partir de uma intensa conjugação de gêneros narrativos do passado [...] com outros gêneros narrativos durante muito tempo colocados nas margens ou até fora do campo institucional da literatura" (Reis, 2018, p. 39). Por isso, a proposta do jogo de tabuleiro $O$ cortiço é a de recriar a atmosfera do romance azevediano, especialmente referindo-se aos personagens e a episódios do enredo, buscando uma interação entre os participantes. O objetivo do jogo, similar ao objetivo de João Romão, após a inveja em torno do título de barão que o vizinho Miranda adquire, é ser o primeiro a juntar a quantia de 100 mil-réis e comprar um título de barão. Para tal, é preciso que o jogador construa casas e receba aluguéis dos inquilinos, contando, também, com ações que tanto lhe podem beneficiar, quanto prejudicar os demais competidores. Assim, vive-se a dinâmica do protagonista, traçando uma estratégia para "enriquecer".

Cada jogador inicia com o seu próprio tabuleiro quadriculado, com 60 quadrados e dividido em três áreas especificadas por cores diferentes (15 verdes, 25 amarelos e 20 azuis) (Figura 1). Duas estruturas fixas devem ser inseridas: a Venda (disposta numa área de 3 quadrados), simbolizando o comércio e a estalagem de João Romão, e a Bica (disposta numa área de 1 quadrado), simbolizando o espaço privilegiado em que as lavadeiras se concentram e o próprio cortiço se aglomera. Sobre essa última, à medida em que o jogo avança, tal peça também se modifica, passando de Bica para Chafariz, quando se atingem os 50 mil-réis em dinheiro. No romance, percebe-se essa evolução, pois, no início, há a animalização constante de todos os personagens: "Daí a pouco, em volta das bicas era um zunzum crescente; uma aglomeração tumultuosa de machos e fêmeas. Uns, após outros, lavavam a cara, incomodamente, debaixo do fio de água que escorria da altura de uns cinco palmos. O chão inundava-se" (Azevedo, 1981, p. 36). Após o incêndio, por sua vez, João Romão aproveita para reconstruir o cortiço e torná-lo mais refinado, digno de um capitalista:

Mas o cortiço já não era o mesmo; estava muito diferente; mal dava ideia do que fora. O pátio, como João Romão havia prometido, estreitara-se com as edificações novas; agora parecia uma rua, todo calçado por igual e iluminado por três lampiões grandes, simetricamente dispostos. Fizeram-se seis latrinas, seis torneiras de água e três banheiros (Azevedo, 1981, p. 202).

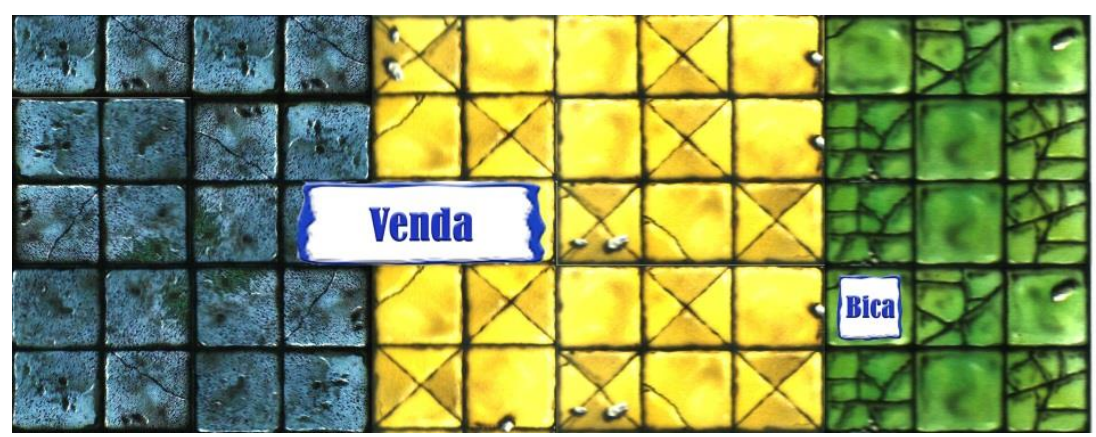

Figura 1 - Tabuleiro do jogo O cortiço, com as peças "Venda" e "Bica".

Fonte: Material desenvolvido no projeto de extensão “Adamastor: Laboratório de Criação de Jogos Literários”. 
Tais peças, fazendo essa evocação inicial da obra, tornam-se estratégicos para o jogador, na medida em que o aluguel das casas construídas ao redor delas torna-se mais caro, devido à "valorização" da localização. Como se nota, na construção da dinâmica de qualquer jogo de tabuleiro (ou de qualquer formulação semiótica em que um conjunto de códigos e de regras estabelece as formas de interação), toda ação deve pressupor, ao mesmo tempo, uma motivação e um encadeamento. A motivação destina-se a aproximar o jogador, ou a afastar os demais, da "vitória", e o encadeamento são as séries de atos que a coerência interna do jogo propõe e que independem das motivações dos participantes. No caso do jogo $O$ cortiço, cada rodada se divide em quatro etapas (1 - Construir; 2 - Alugar; 3 - Agir; 4 - Receber) e cada jogador traça sua estratégia a partir de suas cartas (divididas em três baralhos) e da evolução do jogo.

O primeiro baralho, de Construções, é composto de cartas que indicam áreas de casas com dimensões de um a cinco quadrados e os formatos possíveis (Figura 2), que devem ser dispostas nos limites da área de uma mesma cor, bem como não se sobrepor a outras construções já existentes. Assim, para além do caráter estratégico de organização espacial pelos "encaixes" das construções, há a própria informação dada pelo romance de que os quartos foram logo edificados e prontamente alugados.

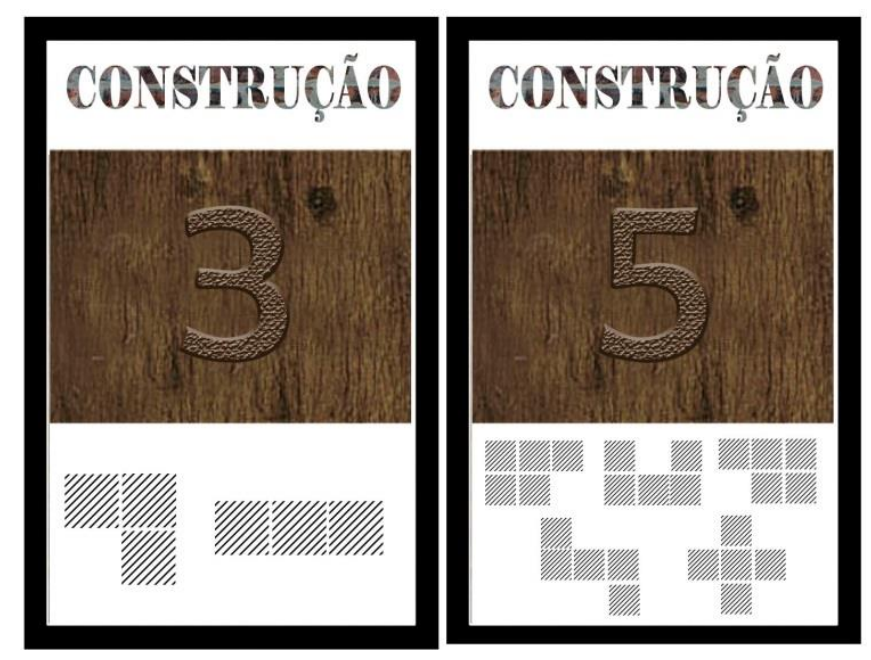

Figura 2 - Cartas de construção para espaços de 3 e 5 quadrados e seus formatos possíveis.

Fonte: Material desenvolvido no projeto de extensão "Adamastor: Laboratório de Criação de Jogos Literários".

Os dois outros baralhos evocam mais diretamente aspectos do enredo d' $O$ cortiço, coadunando-se com a visão de Linda Hutcheon de que "o que é adaptado é o heterocosmo, literalmente um 'outro mundo' ou cosmos, repleto, é claro, dos elementos de uma história cenários, personagens, eventos e situações" (Hutcheon, 2011, p. 37). Por isso, a experiência de revisitação do universo de $O$ cortiço, em seu segundo momento, destina-se à introdução dos inquilinos nas casas construídas. Uma vez que a massa de personagens de Aluísio Azevedo é um dos sustentáculos do romance, e nomes como Rita Baiana, Jerônimo de Jesus, Libório e Pombinha surgem como referência de arquétipos de tipos sociais, a sua utilização no jogo de tabuleiro torna-se elemento fulcral para a coerência interna da adaptação.

A partir de estudos dos personagens, 22 foram selecionados para figurar no baralho dos Inquilinos. Nas cartas, para além de uma ilustração, há um breve resumo contendo as informações mais relevantes sobre a índole e a evolução de cada personagem. Com isso, intenta-se que os participantes, enquanto envolvidos na dinâmica lúdica do jogo, leiam e conheçam (ou rememorem) os personagens e sua função dentro do romance. 
A título de ilustração das informações contidas nas cartas e de como isso influi na interação do jogo, tome-se como exemplo a carta de Rita Baiana (Figura 3). No romance, a sua primeira apresentação já demonstra a sua aura característica de símbolo da beleza brasileira:

No seu farto cabelo, crespo e reluzente, puxado sobre a nuca, havia um molho de manjericão e um pedaço de baunilha espetado por um gancho. E toda ela respirava o asseio das brasileiras e um odor sensual de trevos e plantas aromáticas. Irrequieta, saracoteando o atrevido e rijo quadril baiano, respondia para a direita e para a esquerda, pondo à mostra um fio de dentes claros e brilhantes que enriqueciam a sua fisionomia com um realce fascinador (Azevedo, 1981, p. 61).

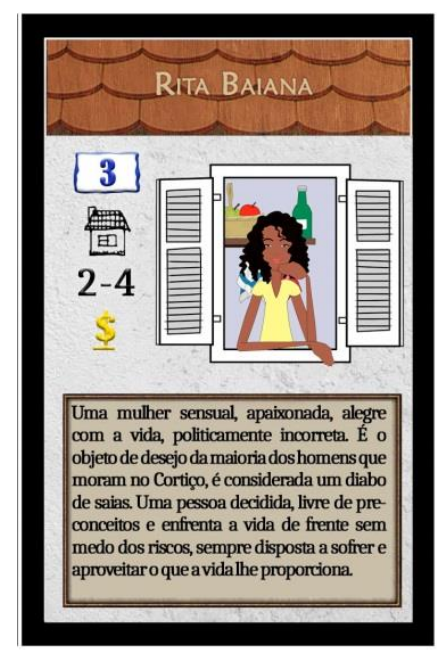

Figura 3. Carta representando a personagem Rita Baiana.

Fonte: Material desenvolvido no projeto de extensão "Adamastor: Laboratório de Criação de Jogos Literários".

Na carta, por sua vez, para além do texto explicativo na parte inferior, há três itens ao lado da ilustração que orientam qual é o funcionamento desse inquilino no jogo:

1) o "número" da casa em azul, ou seja, a construção do tabuleiro que possuir o número "3" sobre ela será a casa ocupada por Rita Baiana;

2) um intervalo de número, logo abaixo de uma ilustração de casa, que representa a dimensão das construções que Rita pode ocupar. Nesse caso, ela pode ocupar construções de dois, três ou quatro quadrados de dimensão;

3) um cifrão, indicando a regularidade com que paga os aluguéis, podendo ser verde (pagando em todas as rodadas), amarelo (pagando em rodadas alternadas) e vermelho (não pagando aluguéis).

Com relação ao "2", distribuíram-se os personagens conforme seu poder aquisitivo ao longo do romance, bem como sua rotina de trabalho ou de ações. Por esse motivo, Firmo (primeiro namorado de Rita Baiana e dado a malandragens) pode ficar em casas de 1 a 3 quadrados, e os Vendedores de loteria (mencionados após a reforma e elevação de status do cortiço) ficam em casas de 4 ou 5 quadrados.

Sobre a regularidade de pagamentos de aluguel, mencionada em " 3 ", essa informação também foi definida conforme o trabalho e compromissos. Assim, embora se receba em todas as rodadas os aluguéis de praticamente todos os inquilinos, há alguns que não pagam regularmente. É o caso de Rita Baiana, Firmo e Porfiro ${ }^{1}$, por serem representados como inquilinos que passam semanas distantes do cortiço. Ou também Bruno e Leocádia ou

\footnotetext{
${ }^{1}$ Embora os dois últimos, no romance, não sejam moradores do cortiço, optou-se por essa "licença poética", de modo a incluí-los no jogo.
} 
Marciana e Florinda, aqui representados como moradores que têm dificuldades de juntar dinheiro para o pagamento. Há também um inquilino não nomeado no romance, um português que se desvia de João Romão para evitar pagar-lhe o aluguel, e que no jogo foi batizado de "Manél", pensando na adaptação como uma forma de (re)interpretação e (re)criação (Hutcheon, 2011, p. 29).

Há, ainda, dois inquilinos que não pagam aluguel, mas que apresentam uma forma alternativa de compensação à ausência, visando a um ganho futuro decorrente das cartas do baralho de Ações. O primeiro é Libório, que, conforme Aluísio Azevedo descreve, "ocupava o pior canto do cortiço e andava sempre a fariscar os sobejos alheios, filando aqui, filando ali, pedindo a um e a outro, como um mendigo, chorando misérias eternamente, apanhando pontas de cigarro para fumar no cachimbo" (Azevedo, 1981, p. 71). A segunda é Paula, "extremamente feia, grossa, triste, com olhos desvairados, dentes cortados à navalha, formando ponta, como dentes de cão, cabelos lisos, escorridos e ainda retintos apesar da idade. Chamavam-lhe "Bruxa'" (Azevedo, 1981, p. 39). Vale ressaltar que tais inquilinos foram inseridos como estratégia, pois o primeiro é condição para que o jogador possa conquistar a ação "Tesouro do Libório", e a segunda garante um acréscimo de prejuízo aos demais jogadores, ao se lançar a ação "Incêndio".

Algo a se considerar, na dinâmica estabelecida até o momento, é que o mero ato de construir e receber aluguéis de inquilinos não garantiria um jogo de estratégia e interação entre participantes, pois cada um poderia se concentrar em seu próprio cortiço e vencer, independente dos demais. Nesse sentido, incluiu-se o terceiro baralho, das Ações, no qual se adaptam algumas das principais situações do enredo do romance, havendo, em destaque, a descrição da ação e, na parte inferior, um breve trecho do capítulo em que se localiza tal acontecimento. Duas delas, supramencionadas, são denominadas Ações Combinadas, por necessitarem de duas cartas conjuntas para que sua ação seja efetivada.

$\mathrm{O}$ incêndio que toma conta do cortiço no capítulo X (deflagrado pela Paula em um acesso de loucura) é determinante dentro do romance, uma vez que ali os personagens passam por uma etapa de transformação e ressurgimento. Muitos perderam tudo que tinham, outros não veem recurso a não ser mudar-se. O único que sai ganhando é João Romão, pois havia feito um seguro do cortiço, de modo que receberá um ressarcimento do banco. No caso do jogo, a ação "Incêndio" acontece quando os participantes lançam na mesa duas dessas cartas da mesma cor (amarela, azul ou verde). Isso faz com que quem jogou a última carta de "Incêndio" escolha um dos competidores e elimine todas as construções existentes na área da cor correspondente - se quem escolhe possuir a Paula entre os seus inquilinos, poderá escolher uma segunda área para queimar do mesmo jogador ou a mesma cor em um outro cortiço.

O "Tesouro de Libório", no romance, tem lugar quando acontece o incêndio no cortiço e João Romão, entrando no quarto do velho, vê este protegendo uma série de garrafas, enquanto tudo queimava. Libório fica preso e morre, ao passo que João Romão pega as garrafas e as esconde no quarto, posteriormente descobrindo que havia dentro delas uma série de notas de dinheiro. Por sua vez, no jogo, quando o jogador lança duas cartas "Tesouro de Libório" na mesa e possui esse personagem como um dos inquilinos, ele recebe 30 mil-réis como ação, ou seja, praticamente um terço do valor necessário para vencer ou o aluguel correspondente a quatro casas de 5 quadrados ou cinco casas de 4 quadrados.

As outras duas Ações Combinadas são: "Polícia" (Figura 4) e "Ataque Cabeça-de-Gato". A primeira, seguindo a descrição de Aluísio Azevedo, refere-se à polícia que, para os moradores do cortiço, "era o grande terror daquela gente, porque, sempre que penetrava em qualquer estalagem, havia grande estropício; à capa de evitar e punir o jogo e a bebedeira, os urbanos invadiam os quartos, quebravam o que lá havia, punham tudo em polvorosa" (Azevedo, 1981, p. 124). Desse modo, no jogo, criou-se o correlato de que o jogador que sofrerá a ação terá seus inquilinos presos, fazendo com que não receba os aluguéis naquela rodada. 
A segunda, o "Ataque Cabeça-de-Gato", refere-se à batalha que acontece entre o cortiço de João Romão e um cortiço vizinho. No romance, tal embate é motivado, dentre outras causas, pela morte de Firmo por Jerônimo e resulta em vários feridos e em um enfrentamento geral com a polícia. No jogo, o participante que recebe tal ação deve descartar metade de seus inquilinos, embora mantenha as construções. Com isso, intenta-se tanto trazer ao horizonte do jogo a cena dos ataques, quanto criar a oportunidade de remover inquilinos indesejados (que não efetuam o pagamento regularmente), mesmo que seja à custa de perder outros inquilinos também.

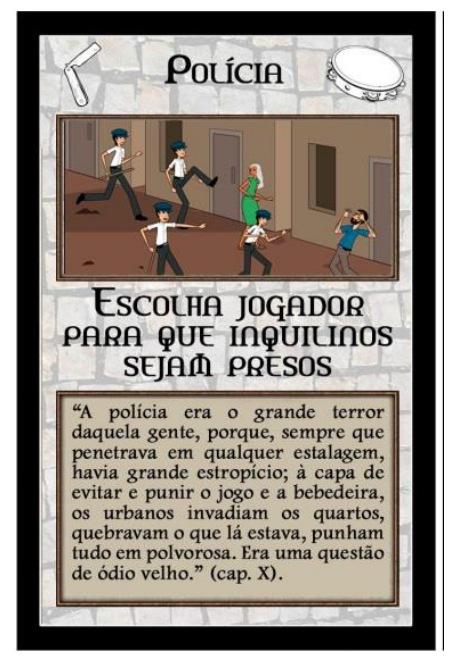

Figura 4. Carta representando a ação "Polícia".

Fonte: Material desenvolvido no projeto de extensão "Adamastor: Laboratório de Criação de Jogos Literários".

Para além das Ações Combinadas, há ainda um conjunto de Ações Simples, ou seja, que podem ser lançadas e imediatamente realizadas entre os jogadores e têm como resultado um ganho ou perda pontuais de dinheiro, ou então um bloqueio de danos. Tais ações têm como objetivo ampliar o lastro de associações com o romance, pois isso abre o texto para novos significados de diálogo intertextual, bem como cria outras experiências estéticas com o universo do cortiço.

A carta "Bertoleza", por exemplo, referindo-se à escrava de quem João Romão se torna "o caixa, o procurador e o conselheiro" (Azevedo, 1981, p. 13), faz seu jogador receber a importância de quatro mil-réis. Logo no início do romance $O$ cortiço, tanto João Romão quanto Bertoleza são retratados em um ambiente adverso em que a adaptação ao meio garantiria a sobrevivência - algo preconizado pela corrente determinista e darwinista. A confiança cega de Bertoleza faz com que ela dê todo o dinheiro ganho a ele, que logo abriu para ela "uma conta corrente, e a quitandeira, quando precisava de dinheiro para qualquer coisa, dava um pulo até à venda e recebia-o das mãos do vendeiro, de 'Seu João', como ela dizia" (Azevedo, 1981, p. 14). No jogo, simbolizando essa coisificação de Bertoleza que se vai agravando cada vez mais no decorrer do romance, Bertoleza se resume a uma carta que repassa um valor financeiro, não influindo em outras ações práticas.

Outra referência ao início do romance é a carta "Material Roubado" (Figura 5), que remete às primeiras estratégias de construção que João Romão:

Estes furtos eram feitos com todas as cautelas e sempre coroados do melhor sucesso, graças à circunstância de que nesse tempo a polícia não se mostrava muito por aquelas alturas. João Romão observava durante o dia quais as obras em que ficava material para o dia seguinte, e à noite lá estava ele rente, mais a Bertoleza, a removerem tábuas, tijolos, telhas sacos de cal, para o meio da rua, com tamanha habilidade que se não ouvia vislumbre de rumor (Azevedo, 1981, p. 16). 


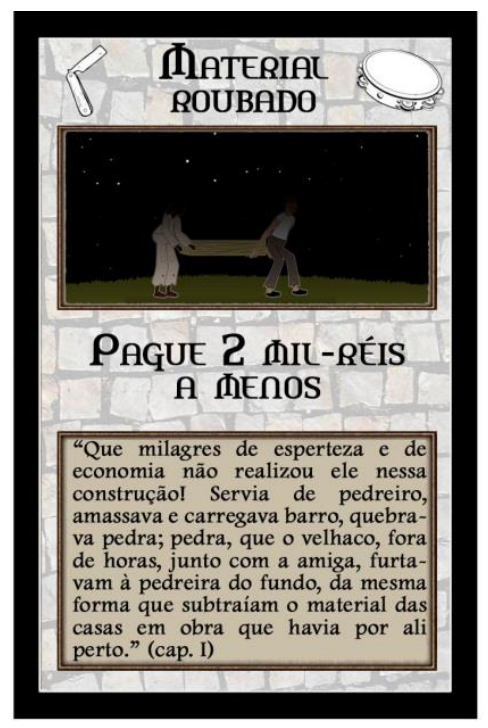

Figura 5. Carta representando a ação "Material Roubado".

Fonte: Material desenvolvido no projeto de extensão "Adamastor: Laboratório de Criação de Jogos Literários".

Esses "milagres de esperteza e de economia" refletem-se, na dinâmica do jogo, no fato de que o participante que lança tal carta paga dois mil-réis a menos na rodada seguinte, quando efetuar novas construções. Levando-se em conta que dois mil-réis é o valor para construir uma casa de 1 quadrado, é como se ela abrisse espaço para mais um inquilino praticamente sem custo. Com essas duas cartas acima descritas, expõem-se ações que refletem a índole egoísta do personagem, interessado apenas em não perder dinheiro e em acumular riquezas.

Algo comumente utilizado em jogos de tabuleiro é uma ação que envolve todos os participantes, não se restringindo a uma interação entre quem usa a carta e quem sofre as consequências dela. No caso desse jogo, estabeleceu-se a carta "Samba" como tal ação. O jogador que lance tal carta receberá de cada participante 3 mil-réis, destinados a uma contribuição para realizar a roda de samba. Isso se justifica, pois, no romance, é na roda de samba de domingo que se congrega o cortiço todo, com o violão e o cavaquinho de Porfiro e Firmo, com a dança de Rita Baiana e com toda a alegria contagiante de todos aqueles moradores. É pelo samba que Jerônimo se "abrasileira", largando os costumes lusitanos (e a esposa portuguesa) e se envolvendo com a cultura brasileira (e com Rita).

Finalizando as Ações Simples, existem duas cartas destinadas a neutralizar ações prejudiciais: "Não, senhor!" e "Armadilha de Jerônimo". A primeira tem como função bloquear as ações de ataque como "Incêndio", "Polícia" ou "Ataque Cabeça-de-Gato", a segunda funciona não apenas como bloqueio, mas também como reversão, fazendo com que quem lançou a carta possa escolher outro jogador para sofrer a ação. Considerando o romance, a primeira carta refere-se à negativa da Florinda, que se esquiva da investida de João Romão:

O vendeiro, ao passar por detrás da Florinda, que no momento apanhava roupa do chão, ferrou-lhe uma palmada na parte do corpo então mais em evidência.

- Não bula, hein?... gritou ela, rápido, erguendo-se tesa.

E, dando com João Romão:

- Eu logo vi. Leva implicando aqui com a gente e depois, vai-se comprar na venda, o safado rouba no peso! Diabo do galego! Eu não te quero, sabe? (Azevedo, 1981, p. 48).

Já a segunda carta remete à emboscada preparada por Jerônimo como vingança por Firmo lhe ter cortado à navalha. Após sua recuperação, um amigo do português embebedou o capoeirista e o levou até uma praia isolada. Uma vez lá, Firmo se viu acuado e "mal tocou com os pés em terra, desferiu um golpe com a cabeça, ao mesmo tempo que a primeira cacetada lhe abria a nuca. Deu um 
grito e voltou-se cambaleando. Uma nova paulada [...] e outras, cada vez mais rápidas, batiam de novo nos pontos já espancados" (Azevedo, 1981, p. 166-167), até a sua morte.

Por certo que ambas as ações não correspondem exatamente à situação do romance, mas nisso reside o conceito de reformatação ou recodificação (Hutcheon, 2011, p. 40). Para a teórica canadense, a partir de leituras de Walter Benjamin, o ato de traduzir (ou adaptar) é o processo de um novo engajamento com o texto original, permitindo-se novas formas de visão e de interação. Desse modo, a partir de uma associação, pode-se formular uma aplicação distinta para algum elemento presente no romance, tornando o jogo de tabuleiro um espaço aberto em que novas narrativas se formam.

Esse novo formato proposto, portanto, cria-se por meio da dinâmica de múltiplos caminhos, em que cada cortiço estabelece a sua rotina de construções e aluguéis ao mesmo tempo em que convive com os perigos de incêndios e ataques inimigos. Há um misto de estratégia e sorte, de rivalidade e cautela, que também subsiste mutatis mutandis nas próprias interações dos personagens no romance. Infelizmente, o jogo não permite um aprofundamento maior nas histórias particulares dos personagens, como a evolução de Pombinha - de flor do cortiço à aliciadora sucessora de Léonie -, as artimanhas de Botelho para casar João Romão com a filha do Miranda e mesmo o trágico final de Bertoleza, mas permite uma breve apresentação da maioria dos personagens e de vários elementos do enredo. E isso se torna uma maneira salutar de tomar conhecimento da obra, ou então de revisitá-la e rememorá-la, fazendo com que o universo de Aluísio Azevedo se expanda para além do livro, por meio de novas artes e novo engenho.

\section{Considerações finais}

As linhas mestras do processo de adaptação de $O$ cortiço para um jogo de tabuleiro foram traçar referências (sutis ou abertas) ao romance, de modo a transmitir uma visão dos personagens e de momentos do enredo, bem como garantir uma jogabilidade dinâmica tanto aos conhecedores da obra, quanto aos que ainda não a leram. Assim, forma-se uma espécie de isonomia entre os jogadores, sem a necessidade da leitura prévia do livro para que o jogo seja realizado, mas que aprofunda a experiência se houver conhecimento dos meandros da história original.

O que se pretendeu com tal atividade, portanto, foi estimular a curiosidade e a redescoberta de textos literários clássicos, pois, para além de constituir-se como um "dever", a apropriação da literatura, por tratar-se de elemento formador da identidade cultural e linguística de um cidadão consciente, é também um "direito" de usufruto da interação verbal, ficcional e imaginativa que a literatura proporciona.

Conforme Antonio Candido, em "O direito à literatura", aponta sobre a necessidade de se aproximar a população dos textos canônicos:

Nas sociedades que procuram estabelecer regimes igualitários, o pressuposto é que todos devem ter a possibilidade de passar dos níveis populares para os níveis eruditos como consequência normal da transformação de estrutura, prevendo-se a elevação sensível da capacidade de cada um graças à aquisição cada vez maior de conhecimentos e experiências (Candido, 2004, p. 188).

A partir dessa visão da literatura como bem incompressível de cunho formativo e humano ao qual todos têm direito, qualquer resgate, evocação ou referência possui valor e importância. $\mathrm{O}$ ato da adaptação dos clássicos, longe de ser um demérito, deve ser considerado como um rebaixamento, não no sentido pejorativo, mas como forma de trazer as obras eruditas novamente ao convívio social e em um contato mais próximo com novas gerações. Com isso, as barreiras do tempo e da linguagem se dissolvem e abre-se caminho para um trânsito entre os níveis que Candido menciona. E os jogos de tabuleiro, como suporte aberto, interativo e lúdico, proporcionam esse momento de ampliação dos conhecimentos, justamente por possibilitar uma experiência não usual de leitura, em que o leitor/jogador traça um plano de ação e determina as peças e personagens que comporão sua narrativa, bem como as situações que permitirão o avanço do jogo. 
Seja em sala de aula ou em momentos de lazer, a prática do jogo como meio de acessar conteúdos literários propõe-se como um modo alternativo e benéfico de fruição literária e que muito contribui para que autores como Aluísio Azevedo, Machado de Assis ou Eça de Queiroz dispam-se da aura de nomes alheios e distantes e assumam lugar à mesa dos novos leitores.

\section{Referências}

AZEVEDO, Aluísio (1981). O cortiço. São Paulo: Abril Cultural.

BARTHES, Roland. (1988). Da obra ao texto. In: BARTHES, Roland. O rumor da língua. São Paulo: Brasiliense.

CANDIDO, Antonio (2004). O direito à literatura. In: CANDIDO, Antonio. Vários escritos. São Paulo: Duas Cidades. p. 169-191.

HUTCHEON, Linda (2011). Uma teoria da adaptação. 2 ed. Florianópolis: Editora UFSC.

MURRAY, Janet H. (2003). Hamlet no holodeck: o futuro da narrativa no ciberespaço. Traduzido por Elissa Khoury Daher e Marcelo Fernandez Cuzziol. São Paulo: Editora Unesp.

PERRONE-MOISÉS, Leila (2016). Mutações da literatura no século XXI. São Paulo: Companhia das Letras.

REIS, Carlos (2018). Estudos literários e ensino da literatura: o jardim dos caminhos que se cruzam. In: CARDOSO, Patrícia da Silva; BUENO, Luís (Orgs.). Nós e as palavras. Cotia: Ateliê Editoral, p. 33-48. 